\title{
11
}

\section{Calibration of Distributed Rainfall- Runoff Model in Hamilton County, Ohio}

\author{
Nestor A. Mancipe, Steven G. Buchberger and Makram T. Suidan
}

Appropriate parameter estimation for the assessment of green infrastructure alternatives in combined sewer systems (CSS) is becoming more important in rainfall-runoff modeling. This chapter studies the calibration of eleven individual storm events in a distributed rainfall-runoff model in SWMM5 for the assessment of green infrastructure in a combined sewer system. High detail rainfall and flow measurements were used. Parameters that represent the area in the model were assumed fixed in this study.

The model independent parameter estimation (PEST) method was used for both parameter estimation and sensitivity analysis. A base flow that includes dry weather flow (DWF) and ground water infiltration (GWI) improved the performance of the simulated hydrographs in the CSS. This study shows that there was not unique set of parameters values that can be used for simulation of the single storm events selected. There was significant variation of the calibration parameter values. Roughness and depth storage in the impervious surfaces were the more sensitive parameters within the calibration process. The sensitivity analysis identified high non-linearity due to high correlation between parameters. There is a systematic bias in the model that needs further research.

\subsection{Introduction}

Combined sewer overflows (CSO) have caused environmental and public health problems nationwide (USEPA, 2001). Grey infrastructure solutions are effective but expensive for control of CSOs. Recently, green infrastructure alternatives have become a suitable solution for CSO control (Jawdy et al.,

Mancipe, N.A., S. Buchberger and M. Suidan. 2012. "Calibration of Distributed Rainfall-Runoff Model in Hamilton County, Ohio." Journal of Water Management Modeling R245-11. doi: 10.14796/JWMM.R245-11. (C) CHI 2012 www.chijournal.org ISSN: 2292-6062 (Formerly in On Modeling Urban Water Systems. ISBN: 978-0-9808853-7-8) 
2010). Green infrastructure promises a way to reduce the cost of proposed grey infrastructure in most CSO long term control plans. Proper rainfall-runoff modeling is needed for the reliable assessment of such green alternatives.

Calibration of a rainfall-runoff model for green infrastructure assessment requires careful input data gathering and the precise selection of calibration variables (Talei et al., 2010). This is particularly important for the placement of decentralized green infrastructure through the watershed in which a high degree of detail of smaller subcatchments along with their drainage networks needs to be modeled (Freni et al., 2002). Therefore distributed rainfall-runoff models became more important for such analysis; but it must be borne in mind that the calibration process could become very complex.

This work was developed in order to evaluate the application of model independent parameter estimation (PEST) in a SWMM5 rainfall-runoff model for Hamilton County, Ohio. To determine the feasibility of this concept, two sewersheds from the West Mill subbasin in south west of Hamilton County are considered. The idea was to calibrate a model which represents physically the CSS and can be used for green infrastructure assessment.

Percentage Impervious Area, Subcatchment Width and Slope are parameters that represent the study area within a SWMM5 model. These are commonly used as calibration variables. If accurate values of these parameters are not produced in the model, the assessment of methods for control of surface runoff will hardly be reliable. The goal was to calibrate variables that are not directly related with the physical representation of the area in SWMM5. This study focused in the calibration of individual storm events from an area of study in Hamilton County, Ohio. Since there is not reliable continuous flow data, eleven storm events with wide ranges of peak flows, total runoff volume and initial moisture conditions were used. Brief descriptions of gathering data for parameters in the area of study are presented. Calibration parameters and the ranges of values for the constrained calibration are defined. Definition of base flows that include DWF and GWI is developed.

Several methods have been studied for calibration of a SWMM5 model (Choi et al., 2002; Fang and Ball, 2007; Gallagher and Doherty, 2008; Kean et al., 2008; Liong et al., 1991; Ovbiedo and Kuch, 1998; Rivas and Roesner, 2009; Talei et al., 2010). The gradient based approach is well known for its computational efficiency and applicability in water surface modeling (Ovbiedo and Kuch, 1998). PEST was used for both parameter estimation and sensitivity analysis. A global local set of parameters was guaranteed through a multi starting point searching driver. Analysis of a set of parameter values from one individual storm event over the dataset was carried out. Further calibration for each individual storm event was completed. Analysis of estimated values and sensitivity of parameters in the rainfall-runoff model was performed. 


\subsection{Study Area and Model Description}

\subsubsection{Area of Study Location and Description}

Hamilton County is located at the south west corner of the state of Ohio. The area of study is in the West Mill subbasin at the southwest corner of Hamilton County. In order to keep manageable the area and based on available observed data, we isolated the area of study within the West Mill subbasin (see Figure 11.1). At the end of this isolated area there is sited a flow monitor in manhole 24805010. CSO 419 is placed at the downstream end of this subbasin. NEXRAD rainfall data for Cincinnati in 5 min steps was applied over the two sewersheds that are within the area of study.

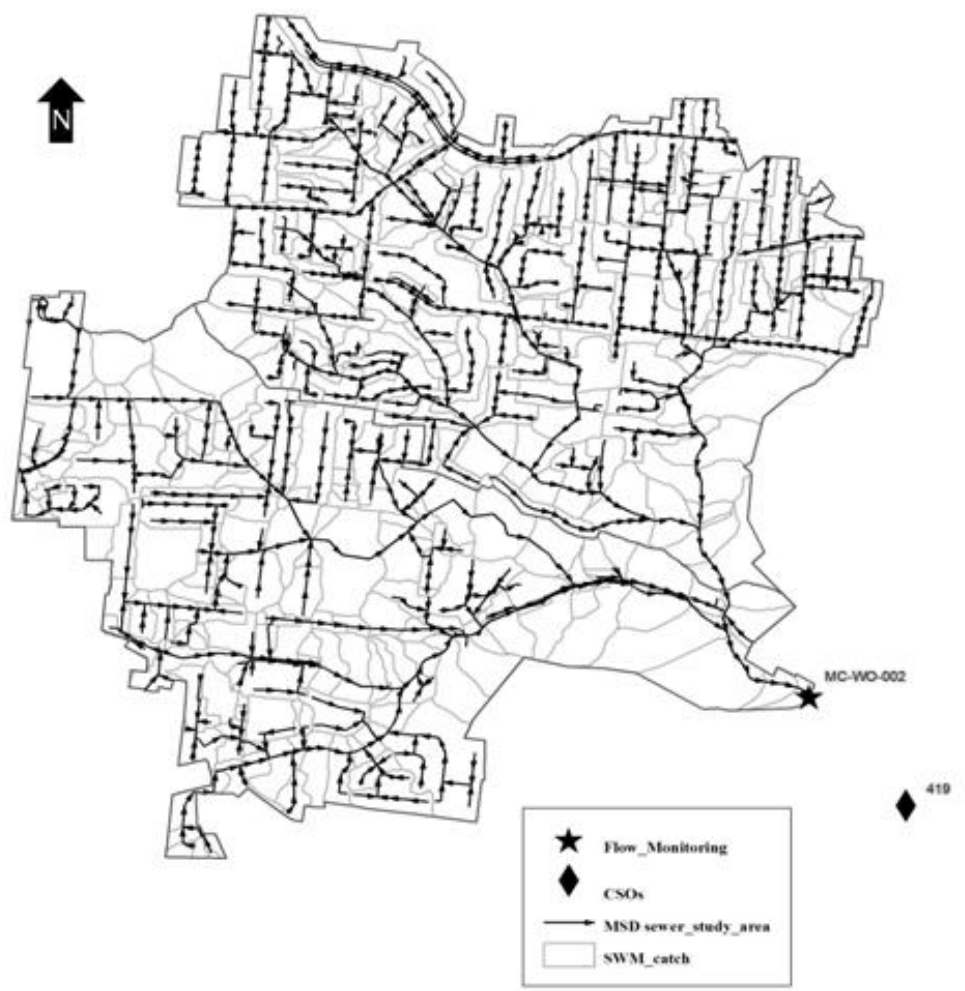

Figure 11.1 Area of study.

The drainage area is 1745 acres (ha) and it has predominant overland slopes of $15 \%$. The direct connected impervious area was estimated to be $25.6 \%$. The area was discretized in 316 subcatchments with predominantly hydrological 
soils groups B and C. The drainage network is composed of more than 500 nodes and links which represent manholes and pipes respectively. Data sources for the input parameters of the SWMM5 model are presented in Table 11.1.

Table 11.1 Description of the area of study.

\begin{tabular}{|c|c|}
\hline PARAMETER & DESCRIPTION \\
\hline & Subcatchments \\
\hline Area & Manually delineated using 2-foot contour data. \\
\hline WidthSubcatchments & $\begin{array}{l}\text { Automatically calculated from Cincinnati Area GIS. A routine } \\
\text { traced all the sewer lengths in a subcatchment area. Then the area } \\
\text { is divided by the longest sewer length. }\end{array}$ \\
\hline Percentage slope & $\begin{array}{l}\text { Calculated from the difference between the highest contour and } \\
\text { the lowest contour for the rise and used the longest length } \\
\text { developed for the width. }\end{array}$ \\
\hline Percentage impervious area & $\begin{array}{l}\text { Composite percent based on land use from parcel shapefile of } \\
\text { Cincinnati Area GIS. (Krabacher, 1999) }\end{array}$ \\
\hline $\begin{array}{l}\text { Roughness overland (n) } \\
\text { impervious area }\end{array}$ & Used general values from literature. \\
\hline $\begin{array}{l}\text { Roughness overland }(n) \\
\text { pervious area }\end{array}$ & Used general values from literature. \\
\hline Depth storage impervious area & Used general values from literature. \\
\hline Depth storage pervious area & Used general values from literature. \\
\hline Infiltration parameters & $\begin{array}{l}\text { Based in Hydrologic soil groups. Group B and C were present in } \\
\text { the area of study. }\end{array}$ \\
\hline Average Dry weather Inflow & $\begin{array}{l}\text { Water use data from Greater Cincinnati Water Works and other } \\
\text { communities in service area. The water use was for the winter } \\
\text { quarter when it was assumed that } 85-90 \% \text { of the water used } \\
\text { would be returned to the sewer. The water use data was geocoded } \\
\text { in GIS then summed all the values in each subcatchment. } \\
\text { Junctions }\end{array}$ \\
\hline Invert Elevation & $\begin{array}{l}\text { Used Metropolitan Sewer District of Greater Cincinnati } \\
\text { (MSDGC) GIS data. When data was not available in, it was } \\
\text { either surveyed or estimated based on pipe slopes. }\end{array}$ \\
\hline Max. Depth & $\begin{array}{l}\text { Found in Cincinnati area GIS data manhole data. } \\
\text { Links }\end{array}$ \\
\hline Shape & Found in Cincinnati area GIS data pipe data shapefile. \\
\hline Max depth & Found in Cincinnati area GIS data pipe data shapefile. \\
\hline Roughness & $\begin{array}{l}\text { Based on the standard published values for different pipe } \\
\text { materials. Pipe material is found in the Cincinnati area GIS data } \\
\text { shapefile. }\end{array}$ \\
\hline Length & Found in Cincinnati area GIS data pipe data shapefile. \\
\hline
\end{tabular}

Calibration parameters were selected from similar studies of SWMM rainfall-runoff modeling (Liong et al., 1991; Rivas and Roesner, 2009; Choi and Ball, 2002; Fang and Ball, 2007). Dongquan et al. (2009) have demonstrated that GIS methods provide a reasonable physical interpretation for SWMM parameters. Thus, Directly Connected Impervious Area (DCIA) and Subcatchment Width were not considered as calibration variables because we wanted to keep the best physical representation of the area. DCIA and width may lead to unrealistic runoff lengths that will affect later green infrastructure analysis (Rivas and Roesner, 2009). The hydraulic configuration of the sewer network 
was provided by the Metropolitan Sewer District of Greater Cincinnati (MSDGC). Parameters selected and their value ranges are presented in Table 11.2 .

Table 11.2 Calibration variables.

\begin{tabular}{|c|c|c|c|}
\hline Subcatchment Parameters & Units & Value & Observations \\
\hline $\begin{array}{l}\text { Roughness for overland flow } \\
\text { impervious area (n-imperv) }\end{array}$ & $\begin{array}{l}\text { dimension- } \\
\text { less }\end{array}$ & $0.010-0.025$ & $\begin{array}{l}\text { Smooth asphalt-cement } \\
\text { rubble. (McCuen et al., } \\
\text { 2002) }\end{array}$ \\
\hline $\begin{array}{l}\text { Roughness for overland flow } \\
\text { pervious area (n-perv) }\end{array}$ & $\begin{array}{l}\text { dimension- } \\
\text { less }\end{array}$ & $0.15-0.8$ & $\begin{array}{l}\text { Short grass-bermuda grass / } \\
\text { Forest. (McCuen et al., } \\
\text { 2002) }\end{array}$ \\
\hline $\begin{array}{l}\text { Depth depression storage } \\
\text { impervious area (s-imperv) }\end{array}$ & in. & $0.05-0.15$ & (ASCE, 2000) \\
\hline $\begin{array}{l}\text { Depth depression storage } \\
\text { pervious area (s-perv) }\end{array}$ & in. & $0.1-0.4$ & $\begin{array}{l}\text { Lawns-pasture-forest } \\
\text { litter. (ASCE, 2000) }\end{array}$ \\
\hline Suction (Suction-B) & in. & $1.0-10$ & \multirow[b]{2}{*}{$\begin{array}{l}\text { Hydrographic soil group } \\
\text { B. Loam, Silt Loam, and } \\
\text { Sandy Clay Loam soil } \\
\text { class. (Rawls et al., 1983; } \\
\text { NRCS, 1982) }\end{array}$} \\
\hline $\begin{array}{l}\text { Hydraulic Conductivity } \\
\text { (Hydcon-B) } \\
\text { Initial deficit (Imd-B) }\end{array}$ & $\begin{array}{l}\text { dimension- } \\
\text { less }\end{array}$ & $0.4-2.4$ & \\
\hline Suction (Suction-C) & in. & $3.0-30$ & \multirow{2}{*}{$\begin{array}{l}\text { Hydrographic soil group } \\
\text { C. Sandy Clay, Silty Clay } \\
\text { and Clay soil class. } \\
\text { (Rawls et al., 1983; } \\
\text { NRCS, 1982) }\end{array}$} \\
\hline $\begin{array}{l}\text { Hydraulic Conductivity } \\
\text { (Hydcon-C) } \\
\text { Initial deficit (Imd-C) }\end{array}$ & $\begin{array}{l}\text { dimension- } \\
\text { less }\end{array}$ & $0.04-0.5$ & \\
\hline
\end{tabular}

\subsubsection{Hydroclimatology}

High resolution 5 min interval NEXRAD rainfall data was obtained. It is the most important input to the model. The rainfall data is subdivided in basins within Hamilton County area. Basins 313 and 314 correspond to the lower and upper region respectively (see Figure 11.1 above). Monthly evaporation average records were found for 2009 for accounting losses (NCDC, 2010a; 2010b).

\subsubsection{Flow Monitoring}

Flow meter MC-WO-002 (manhole 24805010, administered by MSDGC) has flow, level and velocity data for 2009. These were registered with a $5 \mathrm{~min}$ interval.

\subsubsection{Flow Routing}

Dynamic wave was selected for flow routing in SWMM5. Since this method solves the three Saint-Venant equations and accounts for backwater effects, it will produce the best simulated results (Rossman, 2010). 


\subsubsection{Base Line Flow}

The first step of any CSS model is to make sure that the dry weather flows agree with observed data. Ground water infiltration/inflow (GWII) can have a considerable effect on this dry weather flow. Consequently, we assume there is a base flow that includes the dry weather flow and might include some GWII. The USEPA's sanitary sewer overflow analysis and planning toolbox (SSOAP) was used for computing these base line flows. Wet weather days that were preceded by at least three days without rain were selected and filtered through SSOAP and then averaged on a monthly basis to constitute the base line. Figure 11.2 shows the hourly variation of baseline flows per month. Table 11.3 presents the hourly and monthly multipliers for representing the base line flows in the SWMM5 model.

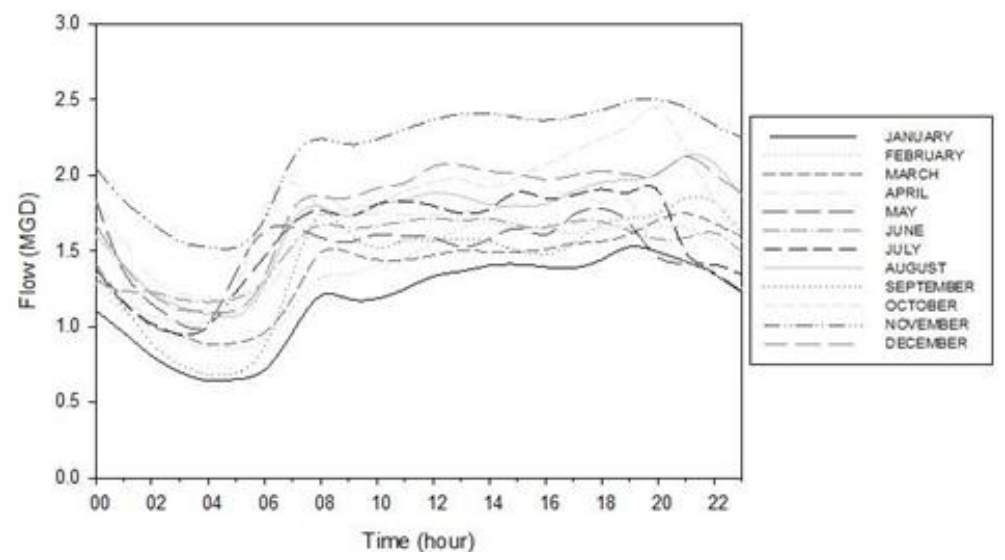

Figure 11.2 Average baseline flow per month in 2009.

Table 11.3 Multipliers for monthly and hourly base line patterns.

\begin{tabular}{cccccccccccc}
\hline \multicolumn{10}{c}{ HOURLY MULTIPLIERS } \\
\hline $0: 00$ & $1: 00$ & $2: 00$ & $3: 00$ & $4: 00$ & $5: 00$ & $6: 00$ & $7: 00$ & $8: 00$ & $9: 00$ & $10: 00$ & $11: 00$ \\
0.904 & 0.759 & 0.665 & 0.613 & 0.6 & 0.64 & 0.8 & 1.001 & 1.055 & 1.053 & 1.078 & 1.106 \\
\hline $12: 00$ & $13: 00$ & $14: 00$ & $15: 00$ & $16: 00$ & $17: 00$ & $18: 00$ & $19: 00$ & $20: 00$ & $21: 00$ & $22: 00$ & $23: 00$ \\
1.122 & 1.153 & 1.129 & 1.123 & 1.123 & 1.14 & 1.167 & 1.185 & 1.193 & 1.191 & 1.151 & 1.047 \\
\multicolumn{8}{c}{} & \multicolumn{8}{c}{ MONTHLY MULTIPLIERS } & & & & \\
Jan & Feb & Mar & Apr & May & Jun & Jul & Aug & Sep & Oct & Nov & Dec \\
\hline 0.782 & 0.886 & 0.939 & 1.192 & 0.967 & 1.065 & 1.077 & 1.157 & 1.045 & 1.101 & 1.453 & 1.206 \\
\hline
\end{tabular}

\subsection{Methodology}

\subsubsection{PEST}

The model independent parameter estimation (PEST) was adapted to calibrate the distributed rainfall-runoff model through slight modification in the 
SMMW5 code. A brief description of PEST theory is presented. Further description of PEST and the utilities used herein are beyond the purpose of this chapter and can be found in detail elsewhere (Doherty, 2010; Moore et al., 2010; Gallager and Doherty, 2007; Skahill and Doherty, 2006).

PEST is considered a frequentist method with linear and nonlinear constrained minimization. PEST minimizes the misfit between model outputs and observed data (objective function) with unknown parameters considered as fixed. PEST as gradient based method offers flexibility and far fewer runs to solve a minimization problem (Gallagher and Doherty, 2007).

The optimum set of model parameters is determined through minimizing the sum of squares deviation between the model generated and the observed flow rates (Doherty, 2010):

$$
\Phi=\sum_{\mathrm{i}=1}^{\mathrm{m}}\left(\mathrm{w}_{\mathrm{i}} \mathrm{r}_{\mathrm{i}}\right)^{2}
$$

where:

$$
\begin{aligned}
\Phi= & \text { objective function, } \\
w_{i}= & \text { ith observation weight, } \\
r_{i}= & \text { difference between the modeled flow and actual flow } \\
& \text { rate for } i \text { th observation, and } \\
m= & \text { total number of time steps in the calibration period. }
\end{aligned}
$$

In the present study, all observations carry equal weighting in the parameter estimation process. (Kean et al., 2008; Doherty, 2010). Constrains for calibration variables were those values in the range shown in Table 11.2 above.

A variant of the Gauss-Marquardt-Levenberg (GML) method is used for a linearizing relationship of model parameters and model generated observations. The linearization is conducted using a Taylor series expansion where the partial derivatives of each model output with respect to every parameter must be calculated at every iteration. For each iteration, the solution of the linearized problem is the current optimal set of parameters. This set is then compared to that of the previous time step to determine when to terminate the optimization process. The parameter vector is updated at each step using the GML algorithm.

Derivatives of the model outputs with respect to its parameters are computed by either forward or central finite differences and stored in the Jacobian matrix. These derivatives provide a measure of the parameters sensitivities at each iteration. The composite sensitivity is provided by PEST as a byproduct of the parameter estimation process. Equation 11.2 defines the composite sensitivity of calibration parameter $i$ :

$$
S_{i}=\left(J^{t} \cdot Q \cdot J\right)_{i i}^{0.5} / m
$$


where:

$$
\begin{aligned}
S_{i} & =\text { composite sensitivity of parameter } \mathrm{i}(\mathrm{i}=1,2,3, \ldots, 10), \\
J & =\text { Jacobian matrix (derivatives of model outputs), } \\
Q & =\text { cofactor matrix (square of observation weights), and } \\
m & =\text { total number of time steps in the calibration period. }
\end{aligned}
$$

Thus $S_{i}$ is the magnitude of the column $i$ in the Jacobian matrix, that corresponds to a calibration parameter $i$, normalized by the number of observations of the time series. No parameter interactions are considered (Tan et al., 2006).

The frequentist approach is very susceptible to finding local optima instead of the global optimum (Doherty, 2010). In order to minimize typical local objective function minima and the existence of different regions of attraction in parameter space a multi starting point driver (PD_MS2) was used along with PEST. The PD_MS2 driver combines the strengths of the global optimization method and the speed of the GML method through incorporating a certain degree of randomness into the parameter estimation process. It searches the global minimum by randomly selecting points in the parameter space as starting values. PEST is run four to ten times the number of adjustable parameters as random parameter sets. This is generally sufficient to warrant a global optimization. (Doherty, 2010; Kean et al., 2008).

\subsubsection{Goodness of Fit}

The Nash-Sutcliffe efficiency $(E f)$, relative volume error $(E V)$, and relative peak error $(E P)$ were used for comparison of goodness of fit. For evaluation purposes a good $E_{f}$ is higher than 0.7 , a good $E V$ is lower than $25 \%$, and a good $E P$ is lower than 0.2. (Kean et al., 2008). These are expressed as follows:

$$
\begin{gathered}
\mathrm{E}_{\mathrm{f}}=1-\frac{\sum_{\mathrm{i}=1}^{\mathrm{m}}\left(\mathrm{Q}_{\mathrm{i}}-\mathrm{Q}_{\mathrm{i}}^{\prime}\right)^{2}}{\sum_{\mathrm{i}=1}^{\mathrm{m}}\left(\mathrm{Q}_{\mathrm{i}}-\overline{\mathrm{Q}}\right)^{2}} \\
\mathrm{EV}=\frac{\mathrm{V}_{\mathrm{o}}-\mathrm{V}_{\mathrm{s}}}{\mathrm{V}_{\mathrm{o}}} \times 100 \\
\mathrm{EP}=\frac{\left|Q_{p o}-Q_{p s}\right|}{Q_{p o}} \times 100
\end{gathered}
$$

where:

$$
\begin{aligned}
Q_{i} & =\text { observed flow rate (MGD) } \\
Q_{i}^{\prime} & =\text { simulated flow rate (MGD), } \\
\bar{Q}^{\prime} & =\text { average observed flow rate (MGD), } \\
V_{o} & =\text { observed runoff volume (MG) }
\end{aligned}
$$


$V_{s}=$ simulated runoff volume $(\mathrm{MG})$,

$Q_{p o}=$ observed peak flow rate (MGD),

$Q_{p s}=$ simulated peak flow rate (MGD), and

$m=$ total number of time steps in the calibration period.

$E_{f}$ is related with the shape of the hydrograph. It ranges from $-\infty$ to 1 . The higher the $\mathrm{E}_{f}$ the better the shape. $E V$ is the percentage of deviation of direct runoff volume. $E P$ is the absolute deviation of peaks flows. The lower the volume error and the peak error the better the performance.

\subsubsection{Datasets and Procedure}

Although several authors have shown that continuous simulation is better for runoff volume estimation than single event, rainfall-runoff models can still be calibrated over a set of representative single events (Kean et al., 2008; Talei et al., 2010). The calibration was made to eleven single storm events from 2009 rainfall data and observed flow measurements. Calibration parameters selected were roughness overland in pervious and impervious areas, depth storage in pervious and impervious areas, and infiltration parameters of the Green-Ampt method (see Equation 11.2.). Table 11.4 shows the characteristics of the eleven individual storm events selected for the calibration analysis. The individual events were selected with a wide range of peak flows, total runoff volume and initial moisture conditions.

Table 11.4 Summary of individual storm events.

\begin{tabular}{|c|c|c|c|c|c|c|c|c|c|c|c|}
\hline Storm Event \# & 1 & 2 & 3 & 4 & 5 & 6 & 7 & 8 & 9 & 10 & 11 \\
\hline Date & $\frac{\stackrel{\infty}{\infty}}{\stackrel{\infty}{\lambda}}$ & $\underset{\text { 方 }}{\stackrel{a}{\rho}}$ & $\frac{\stackrel{\rho}{\rho}}{\stackrel{m}{m}}$ & $\underset{\stackrel{o}{0}}{\frac{0}{6}}$ & $\frac{a}{\stackrel{\sigma}{\sigma}}$ & $\frac{8}{\stackrel{\partial}{6}}$ & $\frac{a}{a}$ & $\begin{array}{l}\stackrel{\text { Oे }}{\mathrm{N}} \\
\text { an }\end{array}$ & 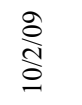 & $\begin{array}{l}\stackrel{0}{\infty} \\
\stackrel{\infty}{0}\end{array}$ & 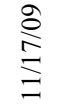 \\
\hline$\overline{\text { Dry V }}$ & 1.30 & 1.38 & 1.38 & 1.57 & 13 & 3.13 & 1.54 & 3.07 & 1.62 & 4.86 & 2.14 \\
\hline $\begin{array}{l}\text { Cum Volume } \\
\text { observed (MG) }\end{array}$ & 3.63 & 4.29 & 5.17 & 10.91 & 14.10 & 40.98 & 7.59 & 16.46 & 5.93 & 45.87 & 4.31 \\
\hline (MGD) & 20.12 & 80.88 & 135.17 & 794.54 & 458.37 & 71715.1 & 196.76 & 83.45 & 35.60 & 484.11 & 149.2 \\
\hline in.) & 0.25 & 0.34 & 0.28 & 0.84 & 0.57 & 0.94 & 0.70 & 1.39 & 0.32 & 2.04 & 0.40 \\
\hline $\begin{array}{l}\text { Storm Duration } \\
\text { (h:min) }\end{array}$ & $1: 30$ & $2: 00$ & $1: 10$ & $4: 25$ & $2: 35$ & $1: 35$ & $1: 40$ & $7: 20$ & $2: 10$ & $8: 45$ & 2:05 \\
\hline $\begin{array}{l}\text { imulation time } \\
\text { (:min) }\end{array}$ & $24: 00$ & $24: 00$ & $24: 00$ & $24: 00$ & $48: 00$ & $48: 00$ & $24: 00$ & $48: 00$ & $24: 00$ & $72: 00$ & $24: 00$ \\
\hline Prior dry days & 3.0 & 2.0 & 7.0 & 5.0 & 0.0 & 2.5 & 9.0 & 11.0 & 4.0 & 1.0 & 17.0 \\
\hline
\end{tabular}

A trial-and-error calibration was made in event 8 . This test was made for comparison purposes with the PEST routine. In the mid time event 8 was used for performance of necessary parameters within PEST implementation when used with PD_MS2. A final calibration was run for the best set of parameters in this event. 
The next step was to evaluate the set of parameters of calibrated event 8 in the other storm events. Model results were analyzed. Significant differences were found between observed and simulated data. Therefore each storm event was calibrated through the PEST calibration routine. Even though some calibrated storm events improve the goodness of fit, there was a considerable discrepancy in $E V$ and $E P$ values. The price for improving the goodness of fit was significant variations in the set of parameters values

\subsection{Results and Discussion}

\subsubsection{Performance of Event 8.}

Roughly two weeks of manual trial and error lasted for finding of the best set of parameters. The changes in the parameter values were done based in the goodness of fit and the behaviour of the results. Results for trial and error are shown in Table 11.5.

Table 11.5 Calibrated parameters for event 8.

\begin{tabular}{|c|c|c|c|c|c|c|c|c|c|c|}
\hline \multirow[b]{3}{*}{ 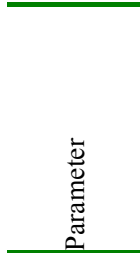 } & \multirow[b]{3}{*}{ } & \multirow[b]{3}{*}{$\begin{array}{l}\vec{d} \\
\stackrel{0}{1} \\
\stackrel{0}{=}\end{array}$} & \multirow[b]{3}{*}{ 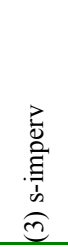 } & \multirow[b]{3}{*}{ 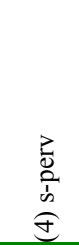 } & \multicolumn{6}{|c|}{ Green-Ampt infiltration } \\
\hline & & & & & \multicolumn{2}{|c|}{ Suction } & \multicolumn{2}{|c|}{ Hydcon } & \multicolumn{2}{|c|}{ Imd } \\
\hline & & & & & 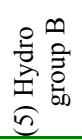 & 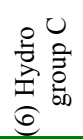 & 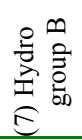 & 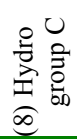 & 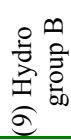 & 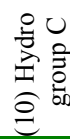 \\
\hline $\begin{array}{l}9 / 20 / 09 \\
\text { Trial-error }\end{array}$ & 0.02 & 0.30 & 0.15 & 0.25 & 3.5 & 3.5 & 1.0 & 1.0 & 0.25 & 0.25 \\
\hline $\begin{array}{l}\text { 9/20/09 } \\
\text { PEST }\end{array}$ & 0.025 & 0.386 & 0.15 & 0.216 & 2.62 & 3.61 & 0.68 & 0.32 & 0.25 & 0.27 \\
\hline
\end{tabular}

The best combination of PEST internal variables for addressing the calibration with PD MS2 was selected through different calibration trials with the single event 8 (2009 0920$)$. The best set of parameters for event 8 through PEST is shown in Table 11.5.

For this event two days of iteration of the routine lasted with the set of parameters. Time that compared with the trial and error is reduced considerably. Figure 11. 3 shows the good behaviour of the simulated hydrograph with respect to the observed data from the set of parameters found by PEST. After these parameters were applied in each storm event, significant differences were found as shown in Table 11.6. The set of parameters values was not able to simulated shape, volume, and peaks in all the observed hydrographs, with low $E_{f}(<0.7)$, high $E V(>25 \%)$, and high $E P(>0.2)$. 


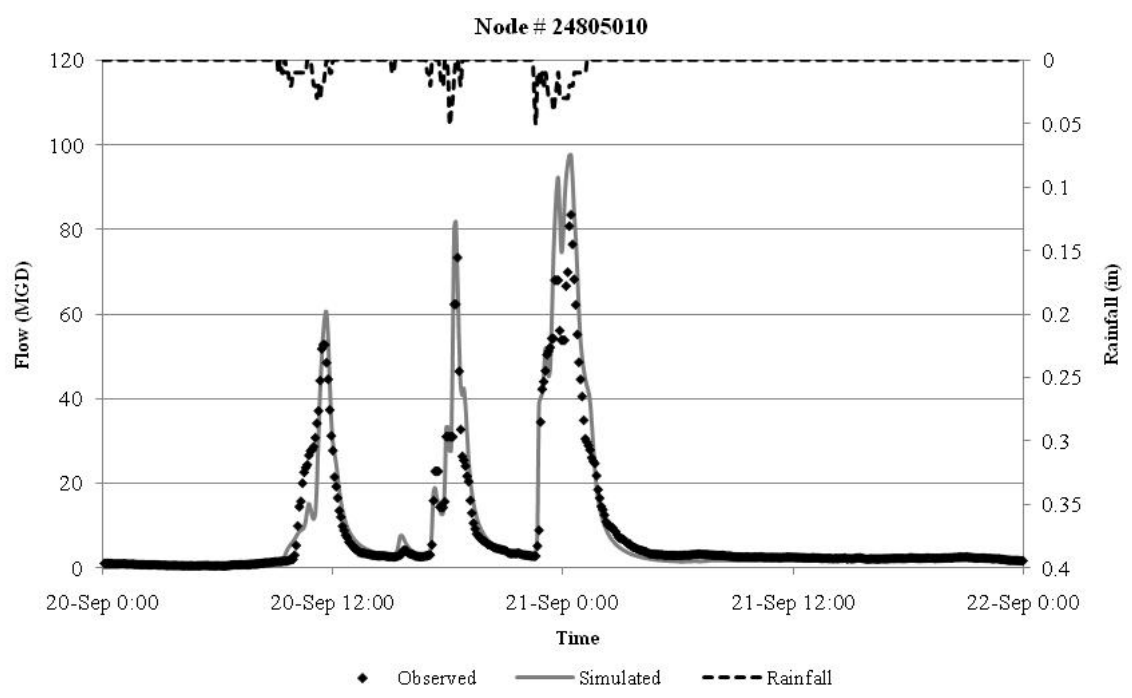

Figure 11.3 Observed and simulated hydrographs for calibrated storm event 8.

Table 11.6 Evaluation of events with the parameters from event 8.

\begin{tabular}{|c|c|c|c|}
\hline \multirow[b]{2}{*}{ Event } & \multicolumn{3}{|c|}{ Goodness of fit } \\
\hline & $E_{f}$ & EV (\%) & EP \\
\hline 1 & 0.47 & 34.66 & 0.15 \\
\hline 2 & 0.24 & 9.63 & 0.51 \\
\hline 3 & 0.63 & 49.48 & 0.56 \\
\hline 4 & 0.86 & 10.97 & 0.05 \\
\hline 5 & 0.40 & 58.25 & 0.82 \\
\hline 6 & 0.34 & 74.40 & 0.82 \\
\hline 7 & 0.88 & -12.86 & 0.04 \\
\hline 8 & 0.70 & -9.26 & 0.17 \\
\hline 9 & 0.54 & 48.04 & 0.24 \\
\hline 10 & 0.65 & 44.48 & 0.47 \\
\hline 11 & 0.49 & -50.08 & 0.29 \\
\hline
\end{tabular}

\subsubsection{Calibration of Each Independent Storm Event}

The purpose of this test was to identify variations in the set of parameters for each storm event and to find patterns for estimation of common set of parameters in the eleven storm events. A calibration for each storm event was made using same configuration as found for event 8 in PEST. Results from this test are shown in Table 11.7 and Figure 11.4. 
Table 11.7 Results from independent calibration of events.

\begin{tabular}{|c|c|c|c|c|c|c|c|c|c|c|c|c|c|}
\hline \multirow{3}{*}{ Event } & \multirow{2}{*}{\multicolumn{4}{|c|}{ Parameter }} & \multirow{2}{*}{\multicolumn{2}{|c|}{ Suction }} & \multirow{2}{*}{\multicolumn{2}{|c|}{ Hydcon }} & \multirow{2}{*}{\multicolumn{2}{|c|}{ Imd }} & \multicolumn{3}{|c|}{ Goodness of fit } \\
\hline & & & & & & & & & & & $\mathrm{E}_{\mathrm{f}}$ & EV & EP \\
\hline & 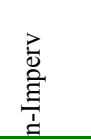 & $\begin{array}{l}\frac{1}{0} \\
\stackrel{0}{!} \\
=\end{array}$ & 悹 & $\begin{array}{l}\vec{D} \\
\frac{1}{b} \\
\frac{1}{n}\end{array}$ & 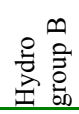 & 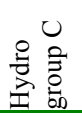 & 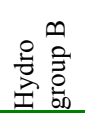 & 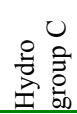 & 莺 & 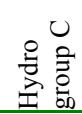 & & & \\
\hline 1 & 0.025 & 0.150 & 0.062 & 0.100 & 1.620 & 5.870 & 1.090 & 0.312 & 0.261 & 0.247 & 0.65 & 0.19 & 48.73 \\
\hline 2 & 0.025 & 0.150 & 0.122 & 0.100 & 1.000 & 3.233 & 1.569 & 0.128 & 0.237 & 0.302 & 0.37 & 0.49 & 19.52 \\
\hline 3 & 0.025 & 0.497 & 0.050 & 0.228 & 2.670 & 15.400 & 1.290 & 0.312 & 0.310 & 0.457 & 0.73 & 18.74 & 38.19 \\
\hline 4 & 0.010 & 0.250 & 0.050 & 0.150 & 1.001 & 3.503 & 0.999 & 0.299 & 0.250 & 0.250 & 0.86 & 0.36 & 1.22 \\
\hline 5 & 0.025 & 0.328 & 0.050 & 0.177 & 1.556 & 6.821 & 1.123 & 0.305 & 0.276 & 0.328 & 0.40 & 38.78 & 79.59 \\
\hline 6 & 0.025 & 0.150 & 0.050 & 0.100 & 1.230 & 3.000 & 1.083 & 0.040 & 0.269 & 0.100 & 0.48 & 56.42 & 73.13 \\
\hline t & 0.010 & 0.250 & 0.150 & 0.152 & 1.034 & 3.546 & 1.051 & 0.314 & 0.270 & 0.258 & 0.87 & -10.80 & 6.85 \\
\hline ס & 0.025 & 0.386 & 0.150 & 0.216 & 2.623 & 3.610 & 0.678 & 0.318 & 0.249 & 0.265 & 0.68 & -7.55 & 17.14 \\
\hline 9 & 0.025 & 0.150 & 0.057 & 0.100 & 1.000 & 3.000 & 0.400 & 0.224 & 0.200 & 0.100 & 0.79 & 20.71 & 10.15 \\
\hline 10 & 0.011 & 0.150 & 0.050 & 0.100 & 1.857 & 3.000 & 1.037 & 0.500 & 0.311 & 0.100 & 0.66 & 36.92 & 34.77 \\
\hline 11 & 0.025 & 0.251 & 0.150 & 0.150 & 1.005 & 3.534 & 1.002 & 0.297 & 0.251 & 0.251 & 0.49 & -25.27 & 29.29 \\
\hline Std & 0.007 & 0.116 & 0.046 & 0.048 & 0.637 & 3.685 & 0.299 & 0.118 & 0.032 & 0.109 & 0.18 & 24.76 & 25.92 \\
\hline Avg & 0.021 & 0.247 & 0.086 & 0.143 & 1.509 & 4.956 & 1.029 & 0.277 & 0.262 & 0.242 & 0.64 & 11.73 & 32.60 \\
\hline
\end{tabular}

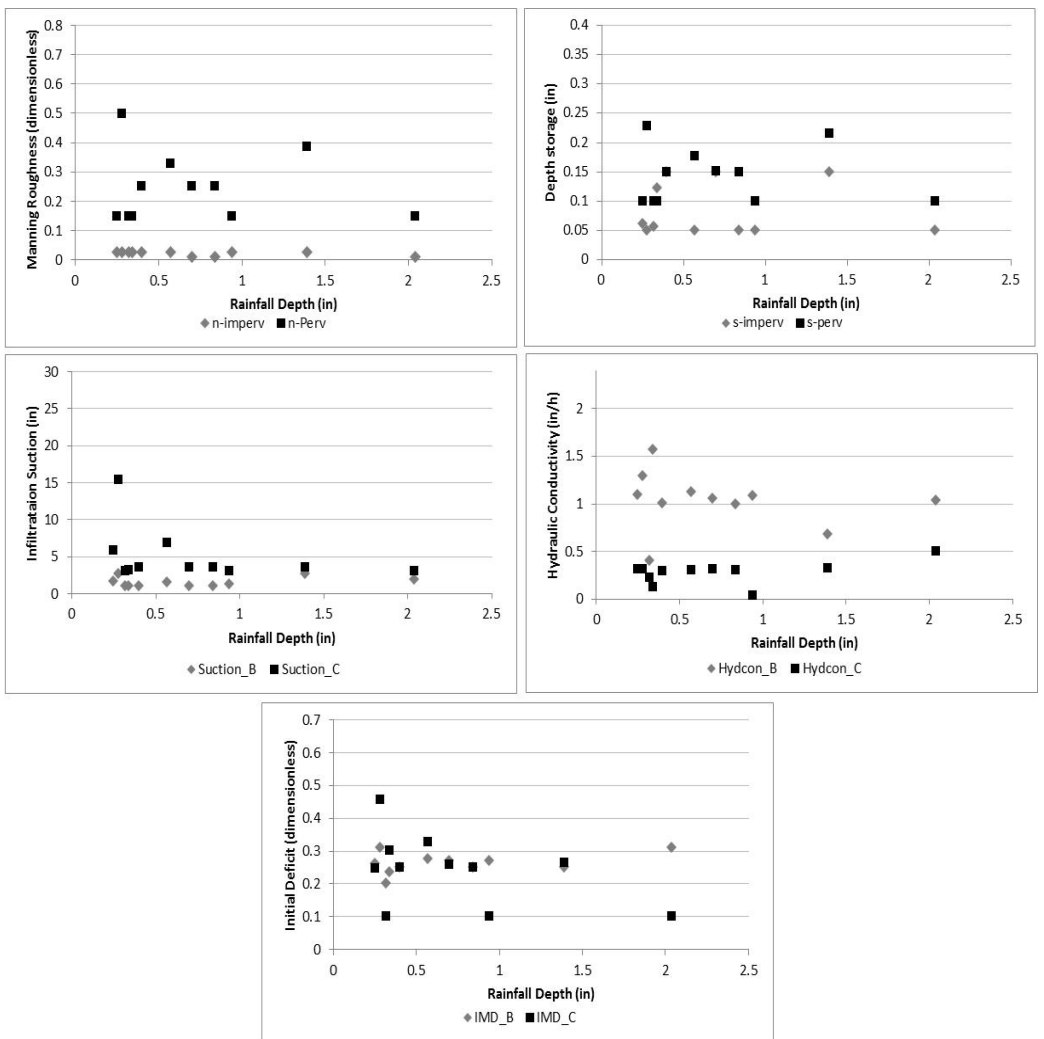

Figure 11.4 Distribution of parameter values for individual storms. 
For the infiltration parameters suction_B, Hydcon_B, and imd_B, values seems to be quite consistent, but less consistent in the hydrologic group $\mathrm{C}$. Variability in hydrologic group $\mathrm{C}$ parameters can be interpreted as responsible of the soil moisture memory because this group has low permeable characteristics. Then for each storm event hold the impact of initial conditions (Kean et al., 2008).

Parameters values of $n$-imperv and s-imperv have a tendency to approach the boundaries of the constrained calibration. This result is consistent with those from sensitivity analysis, where the more sensitive parameters were $n$ imperv and s-imperv (see figure X.5). Therefore in minimizing the objective function the more sensitive parameters were pushed to the boundaries. The apparent values variation in n-perv and s-perv can be attributed to a significant impact of initial conditions at the area of study (Kean et al., 2008). Figure X.5 shows that there is not relationships between the calibrated parameters with the event total rainfall depth. Although Figure X.6 shows a linear relationship between the observed and simulated total runoff volume, we expected to have a 45 degree line. This indicates there is a systematic bias in the model. There was not a common set of parameters that could describe the behaviour of the area of study when event based calibration was performed in the simulated CSS. Pierro et al. (2006) showed similar results when calibrating single storm events in urban storm water.

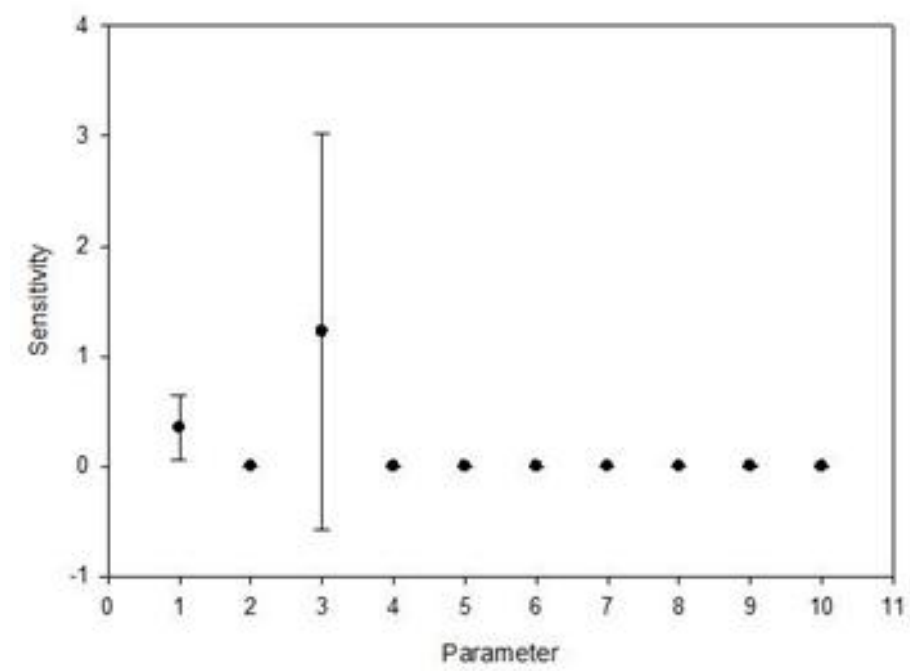

Figure 11.5. Sensitivity analysis from the eleven events with one standard deviation error. 


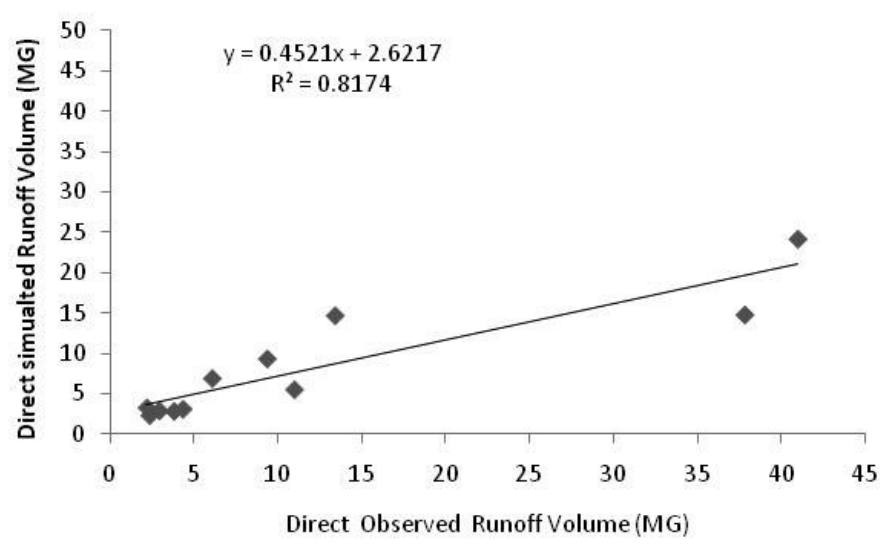

Figure 11.6. Correlation of total observed and total simulated runoff volume.

\subsection{Conclusions}

Previous studies showed that distributed rainfall-runoff models can be calibrated over a set of representative individual storm events having moderate impact of initial moisture memory. This study demonstrates that there is not a unique set of parameters that can be used for simulating the eleven single storm events in the area of study.

Some events were calibrated successfully, though. A considerable change of the values of the calibration parameters values were found from storm to storm. A base line that includes DWF and GWII improved the simulations of a CSS. As expected soils with low permeability characteristics had significant variation between storm events compared with soils of medium permeability. When sensitive parameters DCIA, width, and slope are not considered in the calibration process, roughness and depth storage of impervious area became the more sensitive parameters. Values of these sensitive parameters were pushed to the boundaries of the constrained calibration. This behaviour could be explained by significant impact of initial conditions and misrepresentation of the geometrical configuration of the area in the model (DCIA and Width).

High nonlinearity of parameters selected in this study was confirmed from significant differences in the set of parameter for each event and the sensitivity analysis. There is a systematic bias in the model that needs further research. It is recommended comparing and checking values of parameters that physically represents the area in the model such as DCIA, width, and slope. Calibration of continuous storm events is advice. 


\section{Acknowledgments}

The authors gratefully acknowledge the encouragement of Dr. Ting Lu from Metropolitan Sewer District of Greater Cincinnati who provides important ideas and data sets. Dr. Doherty is acknowledged for his invaluable help in PEST implementation with SWMM5. Also, we acknowledge the University of Cincinnati for financial assistance in this project.

\section{References}

American Society of Civil Engineers. (2000). Design and Construction of Urban Stormwater Management Systems. Manuals And Reports on Engineering Practice No. 77. ISBN 978-0-87262-855-7.

Choi, K. and Ball, J. (2002). Parameter estimation of urban runoff modeling. Urban Water. Elsevier. 31-41.

Doherty, J. (2010). PEST: Model-Independent Parameter Estimation, User manual: 5th Edition. Watermark Numerical Computing, Brisbane, Australia. Available in: http: \www.pesthomepage.org.

Doherty, J. (2008). PEST: Model-Independent Parameter Estimation Surface Water Utilities. Watermark Numerical Computing and University of Idaho. Brisbane, Australia. Available in: http: $\| w w w . p e s t h o m e p a g e . o r g$

Dongquan, Z., Jinign, C., Haozheng, W., Quinyuan, T., Shangbing, C. and Zheng, S. (2009). GIS-based urban rainfall-runoff modeling using an automatic catchment discretization approach: a case study in Macau.Journal Environmental Geology. Vol 52. Issue 2. 465-472.

Fang, T. and Ball, J. (2007). Evaluation of spatially variable control parameters in a complex catchment modeling system: a genetic algorithm application. Journal of Hydroinformatics. 163-173

Freni, G., Schilling, W., Saegrov, S., Milina, J. and Konig, A. (2002). Catchement-wide efficiency analysis of distributed stormwater management practices: the case study of Baerum (Norway). Urban drainage 2002. ASCE. 1-14.

Gallagher, J. and Doherty, J. (2007). Parameter estimation and uncertainty analysis for a watershed model. Environmental Modeling and Software. 1000-1020.

Jawdy, C., Reese, A. and Parker, J. (2010). The potential of Green Infrastructure practices to reduce CSO as examined in Nashville, Tennessee. World Environmental and Water resources Congress. ASCE. 3452.

Kean, S., Chye, L., Shuy, E., Yat-Man, E. and Wan, L. (2008). Performances of Rainfallrunoff Models Calibrated over Single and Continuous Storm Flow Events. Journal of Hydrologic Engineering, 13, 597.

Krabacher, M. (1999). CSO modeling using RUNOFF and TRANSPORT modules of SWMM. 26th Annual Water Resources Planning and Management Conference. ASCE.

Liong, S., Chan, W. and Lum, H. (1991). Knowledge-based System for SWMM Runoff Component Calibration. Journal of Water Resources Planning and Management. Vol. 117, No. 5.

McCuen, R., Johnson, P. and Ragan, R. (2002). Highway Hydrology. Hydraulic Design Series Number 2, Second Edition. FHWA-NHI-02-00. U.S Department of transporta- 
tion. 2-23. Available at

http://www.fhwa.dot.gov/engineering/hydraulics/library_arc.cfm?pub_number=2\&id $=6$.

Moore, C., Wöhling, T. and Doherty, J. (2010). Efficient regularization and uncertainty analysis using a global optimization methodology. Water Resources Research. Vol. 46 W08527, doi:10.1029/2009WR008627.

National Climatic Data Center. (2010a). Normal monthly evaporation for United States of America. Available in: http://www.ncdc.noaa.gov/oa/ncdc.html.

National Climatic Data Center. (2010b). Normal monthly precipitation 1971-2000 for United States of America. Available at http://www.ncdc.noaa.gov/oa/climate/online/ccd/nrmlprep.html. Greater Cincinnati, AP.

Natural Resources Conservation Service. (1982). Soil survey of Hamilton County, Ohio. available in: http://soils.usda.gov/survey/online_surveys/ohio/\#hamilton1982.

Ovbiedo, T. and Kuch, A. (1998). Non-linear parameter estimation of an urban runoff model using XP-SWMM32 and PEST. Water resources and the urban environment, proceedings of the 25th annual conference on water resources planning and Management. 247-252.

Pierro, F., Khu, S. and Savic, D. (2006). From single-objective to multiple-objective multiple rainfall events automatic calibration of urban storm water runoff models using genetic algorithms. Water Science \& technology. Vol 54. No. 6-7. 57-64

Rawls, W.J., Brakensiek, D.L. and Miller, N. (1983). Green-Ampt infiltration parameters from soils data. Journal of Hydraulic Engineering. ASCE, 109:62-70.

Rivas, I. and Roesner, L. (2009). Design and Implementation of Optimized Hydrologic Unit Watersheds for Rainfall -Runoff Modeling. World environmental and Water Resources Congress 2009. 6347.

Rossman, L. (2010). Storm Water Management Model user's manual. Version 5.0. National Risk Management Research Laboratory. USEPA. (EPA-600/R-05/040).

Skahill, B. and Doherty, J. (2006). Efficient accommodation of local minima in watershed model calibration. Journal of Hydrology, 329, 122-139.

Talei, A., Chye, L. and Quek, C. (2010). A novel application of a neuro-fuzzy computational technique in event-based rainfall modeling. Journal Experts systems with applications. Elsevier. 7456-7468.

Tan, Y., Reed, P., Wagener, T. and Van Werkhoven, K. (2006). Comparing sensitivity analysis methods to advanced lumped watershed models identification and evaluation. Journal Hydrology and Earth System Sciences. 3333-3395.

USEPA. (2001). Report to Congress. Implementation and Enforcement of the Combined Sewer Overflow Control Policy. Office of Water. (EPA-833-R-01-003). 